\title{
Ideological differences
}

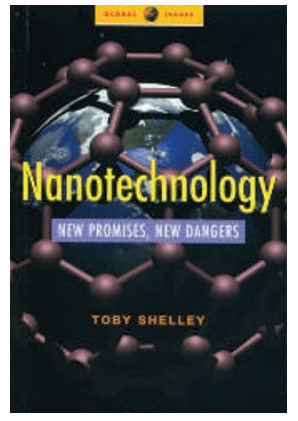

Interest in the interactions between nanotechnology and society is on the rise and is attracting interest from many different communities including academics, policy makers, politicians, pressure groups, activists, celebrities and journalists. This book surveys the social implications of nanotechnology from the perspective of a diffuse international movement that distrusts market economies and worries that any new technology will be disadvantageous to workers and poor countries.

This perspective does not come with a label attached, such as Green or Marxist, but it is reminiscent of the way that the Luddites attacked new technology in the early 1800 s because they had no other way of defending the rights of workers in a period of falling wages and increasing unemployment. It defines social justice largely in terms of equality, rather than accepting that the rich and powerful might have earned their positions, and argues that new technologies will always increase injustice by giving more power to the ruling classes.

The author, who is a journalist for the Financial Times, takes this ideological perspective for granted. He is, nonetheless, refreshingly self-critical, showing an awareness that the impact of nanotechnology will depend upon technical questions that have not yet been answered, and also on the socio-political context in which it is developed. However, the footnotes cite media reports about new developments in nanotechnology, and position papers from organizations with similar views, rather than technical publications. This means that the technical sophistication of the book leaves something to be desired. For example, the author refers to a news report about a switch that operates at millions of cycles per second, adding that this is much faster than laptop computers, when in fact the clock speed of a modern laptop is more than a thousand million cycles per second.
As a cultural document produced by a social movement, the book has a serious limitation that I believe the movement itself shares: the lack of an explicit intellectual tradition of scholarship. For all its faults, Marxism had an intellectual tradition, expressed in a vast library of publications that developed the ideas in some depth. This book does not place its arguments in a well-defined theoretical context, although it is part of a series of books that are critical of the global capitalist system and might fit into the neo-Marxian analysis called 'world systems theory'.

The movement's initial image of nanotechnology included the notion that self-reproducing nanoscale robots would take over production tasks from human beings and could ultimately threaten human life. Refreshingly, the author acknowledges that this view is probably wrong, although he does not seem to realize that the notion of rampaging nanobots can be traced back to the original use of the word robot in a play called R. U.R. (Rossum's Universal Robots) by the Czech author Karel Čapek. In this play, which was first performed in 1921, the robots represented the dehumanized working class revolting against the human ruling class.

On a more realistic level, the book expresses concern that nanotechnology may cause unemployment among industrial workers and the producers of some raw materials in developing countries. While the imaginary nanobots might conceivably cause mass unemployment, Shelley believes that more modest nanotechnologies could also overturn the labour theory of value, which is the fundamental idea of Marxist economics. At the same time, he expresses hope that nanotechnology could benefit humanity if, somehow, it could be rescued from the forces of capitalism.

In a chapter titled "Nanotechnology Goes to War," and another about nanowars and domestic spying, Shelley describes efforts to develop nano-enabled sensors for the detection of chemical, biological and radiological weapons, and goes on to discuss the importance of gathering information about both citizens and foreign nationals for the defence and intelligence communities.

Elsewhere, a chapter on technological convergence correctly notes that much of the societal impact of nanotechnology is likely to be in collaboration with other technologies, most obviously biotechnology and information technology, and most controversially in methods for influencing the human brain or creating artificial intelligences. Despite the vast scope of technological convergence, this chapter is remarkably myopic, relying heavily on a modest 2004 European report on the topic, and not even citing a more substantial report, Converging Technologies for Improving Human Performance (www. wtec.org/ConvergingTechnologies/), which followed a 2001 conference on this subject that was sponsored by the US National Science Foundation and Department of Commerce.

The book similarly ignores another pioneering report from the US, Societal Implications of Nanoscience and Nanotechnology (www.wtec.org/loyola/ nano/societalimpact/nanosi.pdf), which actually established the social dimension of nanotechnology as a topic worthy of study and concern in its own right. These omissions reinforce the observation that this book is useful as an introduction to a particular ideology, but is not a balanced treatment of the actual potential of nanotechnology.

\section{William Sims Bainbridge}

William Sims Bainbridge is in the Division of Information and Intelligent Systems at the National Science Foundation, Arlington, Virginia 22230. The views expressed in this article do not necessarily represent those of the NSF.e-mail: wbainbri@nsf.gov 